Exceptions were an entry made by a psychiatrist and four by one general practitioner (GP). In addition appoint-

original papers ments with other professionals were also noted by CMHT workers, mainly psychiatric out-patient appointments, but also two appointments with a GP and a Care Programme Approach review. Comparison of the entries with CMHT notes showed that they were used for an average of $72 \%$ of contacts with the team.

\section{Discussion}

Although this study is of a small sample using patientheld records and included no standardised outcome measures, it has, nevertheless, two important attributes. The setting is a naturalistic clinical situation in a deprived urban environment and the follow-up period longer than previous studies. In its findings, the proportion of respondents using the records was lower at $62 \%$ than at the time of the original survey ( $82 \%)$. However, the average length of time it had been used had increased by nearly 4 years. Consistency of use remained fairly stable, as $72 \%$ of contacts with staff were being recorded in the patient-held record compared to $74 \%$ of all team contacts in the original study, a decline of only $2 \%$ in 4 years. The range of people writing in the record was smaller at the time of the present study. The users of the record still had a favourable opinion of its usefulness.

The context of the follow-up study was different from the original evaluation, the latter being undertaken as part of a pilot project. At that time a project worker was in place to ensure that professionals and service users were aware of the record and how it could be used. The second study took place after the project, and its attendant support and attention had ended.

It is interesting to note the differences in findings between this study and that of Warner et al (2000), which found a lower rate of usage by patients. Possible reasons for this may include the non-randomisation and consequent self-selection in the present study. This may also account for the client reports of satisfaction found in the present study. Future research could further investigate characteristics of record users, and record refusers / non-users, to identify those groups who find the record most beneficial. Both studies found a certain reluctance among professionals to utilise the record, although this was more marked in the Warner et al (2000) study. Essex et al (1990) reported a similar finding. This suggests that if such records are to be more widely used, the issues of professional reluctance to utilise them should be addressed in future research.

Although there have been a number of pilot projects on patient-held records, this is the only long-term followup survey. The patient-held record continued to be used in the absence of a designated worker to support it and without any other enthusiastic proponent of the project. This would indicate that patient-held records are sustainable in the longer term in a naturalistic clinical setting. They are popular with record holders themselves, who appreciate a number of aspects of the record, such as having information about appointments and telephone numbers and the names of professionals in the one place.

\section{References}

ESSEX, B., DOIG, R. \& RENSHAW, J. (1990) Pilot study of records of shared care for people with mentalillness. BMJ, $300,1442-1446$.

GREASLEY, P., PICKERSGILL, D., LEACH, C., et al (2000) The development and piloting of a patient held record with adult mental health users. Journal of Psychiatric and Mental Health Nursing, 7. 227-231.

LAUGHARNE, R. \& STAFFORD, A. (1996) Access to records and client-held records for people with mental illness. A literature review. Psychiatric Bulletin, 20,338-341.

McGREEVY, P. (1995) Using clientheld records in community nursing

practice. Mental Health Nursing, 15(2) $26-27$

REULER, J. B. \& BALAZS, J. R. (1991) Portable medical record for the homeless mentally ill. BMJ, 303, 446.

STAFFORD, A. \& LAUGHARNE, R. (1997) Evaluation of a client-held record introduced by a community mental health team. Psychiatric Bulletin, 21 $757-759$

WARNER, J.P., KING, M. BLIZARD, R. et al (2000) Patient-held shared care records for individuals with mental illness. Randomised controlled evaluation. British Journal of Psychiatry, 177, 319-324.

*Anna Stafford Occupational Therapist, East London \& the City Mental Health NHS Trust, CPOT, Homerton Hospital, Homerton Row, London E9 6SR, Richard Laugharne Consultant Psychiatrist, Cornwall Healthcare NHS Trust and University of Exeter, Department of Mental Health, Wonford House Hospital, Kenneth Gannon Senior Lecturer in Behavioural Science, Barts and the London, Queen Mary's School of Medicine and Dentistry, School of Occupational Therapy

\title{
A survey of academic provision for old age psychiatry in the UK and Ireland
}

\section{AIMS AND METHOD}

This paper reports the findings of a 1999 survey of academic old age psychiatry staffing and teaching in UK and Irish medical schools.
RESULTS

Just over half had staff established at the level of senior lecturer or above. These schools devoted more time to undergraduate teaching, covered more topics and used a wider range of teaching methods.

\section{CLINICAL IMPLICATIONS}

There is a need for further academic development in old age psychiatry to drive the development of the speciality, and to ensure that all medical undergraduates receive an adequate training in this subject area. 
The Academic Old Age Psychiatry Association (AOAPA) was established in 1998, with the aim of promoting and supporting academic activities and developments in this speciality. The members (currently 51) are old age psychiatrists with substantive university appointments, and others (both medical and non-medical) with substantial research and/or teaching roles in this area. An important objective of the AOAPA is to ensure that there is a section of old age psychiatry in all UK and Irish universities with undergraduate medical schools. To this end, a working party was set up with a remit to determine the current level of provision and identify important gaps; make recommendations regarding the necessary core staffing and resourcing of sections of old age psychiatry; and to make recommendations regarding the core undergraduate curriculum. In order to establish an up-to-date baseline, all UK and Irish undergraduate medical schools were surveyed in 1999 regarding their old age psychiatry establishment, and the undergraduate teaching that they provided in this speciality.

\section{Method}

Medical schools in the UK and Ireland $(n=28)$ were divided into a provided group $(n=15)$, where there was known to be an academic old age psychiatry establishment at senior lecturer level or above, and a nonprovided group ( $n=13$ ) where this establishment was absent (determined through AOAPA membership).

\section{Survey 1: academic establishment and development}

The senior academic old age psychiatrists in the provided schools were sent a questionnaire enquiring about the following: date of establishment of old age psychiatry section; initial staffing establishment; current staffing establishment; reasons for attrition, if any; sources of funding for academic posts; location of old age psychiatry within the faculty (e.g. psychiatry, neuroscience, etc.); links with other departments; and research and teaching activities.

The heads of the departments of psychiatry in the non-provided schools were sent an alternative questionnaire enquiring about the following: clinical academic old age psychiatry establishment below the level of senior lecturer; non-clinical academic establishment in related areas (e.g. dementia research, epidemiology,

psychology); plans for academic developments in old age psychiatry; previous attempts to establish old age psychiatry posts and reasons for failure; and loss of previously established posts and reasons for this.

\section{Survey 2: undergraduate teaching}

All schools were also sent a second questionnaire enquiring about their undergraduate old age psychiatry curriculum, covering whether or not the curriculum included teaching of old age psychiatry; where in the curriculum this teaching took place; duration of attachment to this speciality; form and content of the teaching; student assessment; and past problems and future plans.

original papers

\section{Results}

In England and Wales, 14/19 (74\%) of the schools had clinical academic establishment in old age psychiatry at the level of senior lecturer or above. In Scotland and Ulster, however, none of the schools had such an establishment. In the Irish Republic 1/5 (20\%) of the schools were established at this level. The oldest academic grouping in this sample was established in 1978; the remainder were set up within the past 15 years.

\section{Academic establishment and development: provided schools}

The response rate to this questionnaire was $12 / 15$ (80\%). Table 1 sets out the current academic establishment in old age psychiatry (clinical and non-clinical) in the responding schools. Most schools had increased their numbers of academic staff in old age psychiatry since they were originally established; only one school reported attrition of a post because of lack of suitable applicants. Most academic old age psychiatry units were based in departments of psychiatry $(8,67 \%)$; alternative locations were in neuroscience $(2,17 \%)$, clinical sciences $(1,8 \%)$ and public health/primary care $(1,8 \%)$. All but two schools reported active research links between old age psychiatry and other academic departments. In all but one school

Table 1. Current academic establishment (clinical and non-clinical) of provided medical schools

\begin{tabular}{|c|c|c|c|}
\hline & Number of posts & $\begin{array}{l}\text { Numbe } \\
\text { clinical }\end{array}$ & $\begin{array}{l}\text { of schools } \\
\text { non-clinical }\end{array}$ \\
\hline \multirow[t]{3}{*}{ Professor } & 0 & 4 & 11 \\
\hline & 1 & 7 & 1 \\
\hline & 2 & 1 & \\
\hline \multirow[t]{2}{*}{ Reader } & 0 & 11 & \\
\hline & 1 & 1 & \\
\hline \multirow[t]{4}{*}{ Senior lecturers } & 0 & 2 & \\
\hline & 1 & 7 & \\
\hline & 2 & 2 & \\
\hline & 6 & 1 & \\
\hline \multirow[t]{2}{*}{ Lecturers } & 0 & 3 & 11 \\
\hline & 1 & 9 & 1 \\
\hline \multirow[t]{3}{*}{ Research fellows } & 0 & 9 & 10 \\
\hline & 1 & 3 & 1 \\
\hline & 3 & & 1 \\
\hline \multirow[t]{5}{*}{ Research assistants } & 0 & 8 & 8 \\
\hline & 1 & 1 & 0 \\
\hline & 2 & 2 & 3 \\
\hline & 3 & 0 & 1 \\
\hline & 6 & 1 & 0 \\
\hline
\end{tabular}


the academic old age psychiatrists were involved in the organisation and delivery of undergraduate and post-

original papers were involved in the organisation and delivery of under- graduate teaching in old age psychiatry, and 10/12 (83\%) graduate teaching in psychiatry more generally. In twothirds of the schools, academic old age psychiatrists contributed to the undergraduate MBBS examination (or equivalent)

\section{Academic establishment and development: non-provided schools}

The response rate to this questionnaire was $7 / 13$ (54\%). Of the responders, 2 (29\%) had clinical academic staff in old age psychiatry below the level of senior lecturer and six (86\%) had plans for clinical academic developments in the speciality. Five schools (71\%) had non-clinical academic staff working in areas related to old age psychiatry. Three reported previously unsuccessful attempts to establish clinical academic posts, the problems being lack of resources, an unsupportive university and failure to appoint at interview. One school had lost a previously established post because the NHS funding was withdrawn following failure to appoint.

\section{Undergraduate teaching}

The total number of responses to this questionnaire was 22/28 (79\%): 15/15 (100\%) from the provided schools and $7 / 13(54 \%)$ from the non-provided schools. The

Table 2. Undergraduate teaching of old age psychiatry in provided and non-provided medical schools

\begin{tabular}{|c|c|c|c|}
\hline & $\begin{array}{l}\text { Provided } \\
n(\%)\end{array}$ & $\begin{array}{c}\text { Non-provided } \\
n(\%)\end{array}$ & $\begin{array}{l}\text { Total } \\
n(\%)\end{array}$ \\
\hline \multicolumn{4}{|l|}{ Teaching formats } \\
\hline lectures & 11 (73) & $5(71)$ & $16(73)$ \\
\hline tutorials/interactive & $10(67)$ & $2(29)$ & $12(55)$ \\
\hline clinical attachments & $13(87)$ & $5(71)$ & $18(82)$ \\
\hline other & 5 (33) & $1(14)$ & $6(27)$ \\
\hline \multicolumn{4}{|l|}{ Topic areas covered } \\
\hline dementia & $15(100)$ & $6(86)$ & $21(95)$ \\
\hline delirium & $15(100)$ & $6(86)$ & $21(95)$ \\
\hline affective disorders & $14(93)$ & $6(86)$ & $20(91)$ \\
\hline psychotic disorders & $12(80)$ & $6(86)$ & $18(82)$ \\
\hline service organisation & 11 (73) & $2(29)$ & $13(59)$ \\
\hline other & $5 \quad(33)$ & $0 \quad(0)$ & $5(23)$ \\
\hline $\begin{array}{l}\text { Workbooks/other } \\
\text { documentation }\end{array}$ & $5 \quad(33)$ & $3(43)$ & $8(36)$ \\
\hline \multicolumn{4}{|l|}{ Student assessment } \\
\hline formal examination & $10(67)$ & $5(71)$ & $15(68)$ \\
\hline coursework & $3(20)$ & $4(57)$ & $7(32)$ \\
\hline clinical attachment & $10(67)$ & $4(57)$ & $14(64)$ \\
\hline other & $5 \quad(33)$ & $1(14)$ & $6(27)$ \\
\hline
\end{tabular}

Provided, contains known academic old age psychiatry establishment at senior lecturer level or above; non-provided, absence of academic old age psychiatry establishment at this level. replies are shown in Table 2 . In all of the schools, the undergraduate curriculum contained some theoretical and/or clinical teaching of old age psychiatry, although in one case this was confined to a single lecture. The amount offered varied considerably, ranging from 1 to 40 days, with a mode of $4 / 5$ days. In some of the schools, student exposure to old age psychiatry was variable, depending on individuals' clinical attachments. For the maximum a student could receive, the means were 10.8 days (provided schools) and 6.0 days (non-provided schools). A wide range of teaching formats were reported, the commonest in both provided and nonprovided schools being the traditional methods of clinical attachments, lectures and tutorials. Other methods, such as demonstrations, computer-assisted learning, role-play and problem-based learning, were reported mainly by the provided schools. Only a minority of schools used work books or other documentation as part of their teaching, although a number reported that such materials were under development. A 'core' old age psychiatry curriculum of dementia, delirium, depression and psychotic disorders was taught by the majority of schools; service organisation was less commonly covered; and only the provided schools included subjects such as neurotic disorders, psychological treatments, cognitive assessment and ethical/legal issues in this age group. Student assessment was most commonly by formal examination and assessment of performance during the clinical attachment. Other techniques, such as assessed coursework and objective structured clinical examinations, were less frequently reported.

Six schools (provided: $3 / 15,20 \%$; non-provided: $4 / 7,57 \%$ ) reported that there had been significant obstacles to introducing and maintaining old age psychiatry teaching in the undergraduate curriculum. These included reduction of time available, insufficient academic or clinical staff, uncoordinated teaching across many modules and problems with colleagues in general psychiatry. Ten schools (provided: 5/15, 33\%; nonprovided: $5 / 7,71 \%$ ) said that they currently did not have any plans specifically to revise or expand their undergraduate teaching in old age psychiatry, although some of these commented that the whole of their medical curriculum was currently undergoing revision.

\section{Discussion}

This survey was planned as a comprehensive overview of current old age psychiatry teaching and academic provision for all medical schools in the UK and Ireland. The response rate to this survey was generally good, although there was a relatively poorer return from the non-provided schools. This may have been owing to the lack of a suitable respondent, or the lack of perceived salience of the questionnaires. Consequently, we may have underestimated the poorest end of the spectrum of academic provision and teaching in this speciality.

Several previous studies (Wattis \& Arie 1981, 1984; Wattis 1989; Faire \& Katona 1993; Gregory \& Dening, 1995) have examined the point prevalence of academic 
posts in old age psychiatry and the practice of undergraduate teaching in this speciality in the UK. In comparison with these, our findings suggest there has been a considerable increase over the past decade both in the number of academic posts and in the amount of undergraduate teaching provided. For example, Faire and Katona (1993) reported a median proportion of psychiatry teaching devoted to old age psychiatry of $15 \%$ (range 2.5-25), with a median duration of 6 hours (range 1-14). The findings of the present survey are also better than those recently reported for Australia and New Zealand (O'Connor et al, 1999), where the mean length of old age psychiatry teaching was only 4.2 hours (range 0 7) out of a mean total of 353 hours (1.2\%).

However, there is no room for complacency about the present state of academic old age psychiatry in the UK and Ireland. Just over half the medical schools that responded have established departments in old age psychiatry, and the academic establishment in these provided schools is patchy, for example, four departments do not have a chair. Three departments have no clinical lecturers in old age psychiatry, and these posts are likely to decrease further as the demands of the research assessment exercise result in cutting of posts that are seen as less productive in terms of publications and grant income. This is a worrying development, as lecturers represent the seed corn of the next generation of academics, and this survey has shown there is already a dearth of suitable applicants for some academic posts. Given the planned expansion in medical student numbers and the creation of at least three new medical schools in the UK over the next 5 years, the workforce situation nationally looks increasingly bleak. Some established academic sections of old age psychiatry might not continue to be viable if there is an insufficient critical mass of academics to sustain research output.

Because of demographic ageing, all doctors now need to have a good undergraduate training in the assessment and management of mental disorders in old age. Our findings show that those medical schools with established departments provide more teaching of old age psychiatry and are more likely to embrace new teaching methods. It is worrying that students in some medical schools may not be taught the fundamentals of dementia and delirium, although it is possible that this teaching may be provided elsewhere on their course.
At the postgraduate level, although old age psychiatry is now a major speciality within the UK, with 1512 members of the College Faculty of Old Age Psychiatry (539 consultants, including academics: figures as at 13/11/00), many consultant posts remain unfilled because of an inadequate supply of trained specialist registrars. Recent publications such as Forget Me Not (Audit Commission, 2000) and the National Service Framework for Older People (Department of Health, 2001) are likely to stimulate further development of the speciality. If this is to be driven by uniform excellence in teaching and research, then new ways will have to be found to encourage and train individuals in the subject. Both the NHS and universities need to recognise they have a role in fostering and financing the academic growth of the discipline. It would clearly be desirable for currently non-provided medical schools to set up sections of old age psychiatry, but once again the lack of suitably qualified applicants is likely to frustrate this in the short to medium term. However, it is important to demonstrate the need, and clinical old age psychiatry services associated with non-provided schools should be encouraging and supporting the development of NHS-funded academic posts.

\section{References}

AUDIT COMMISSION (2000) Forget Me O'CONNOR, D.W., CLARKE, D. M. \& Not. London: HMSO.

DEPARTMENT OF HEALTH (2001)

National Service Framework for Older People. London: Department of Health.

FAIRE, G. M. \& KATONA, C. L. E. (1993)

Survey of undergraduate teaching of

old age psychiatry in the United

Kingdom. Psychiatric Bulletin, 17

209-211.

GREGORY, C. A. \& DENING, T. (1995) Teaching old age psychiatry to medical students in England. International Journal of Geriatric Psychiatry, 10, 883-886. PRESNELL, I. (1999) How is psychiatry taught to Australian and New Zealand medical students? Australian and New Zealand Journal of Psychiatry, 33,47-52.

WATTIS, J. P. (1989) Old age psychiatrists in the United Kingdom - their educational role. International Journal of Geriatric Psychiatry, 4, 361-363.

— \&ARIE,T. (1981) Psychogeriatrics: a national survey of a new style of psychiatry. BMJ, 282, 1529-1533.

—\&—(1984) Further developments in psychogeriatrics in Britain. BMJ, 289,778

* James Lindesay Professor of Psychiatry for the Elderly, Division of Psychiatry for the Elderly, University of Leicester, Leicester General Hospital, Leicester LE5 4PW, Cornelius Katona Professor of Psychiatry of the Elderly, Royal Free and University College Medical School， Richard Prettyman Senior Lecturer in Old Age Psychiatry, University of Leicester, James Warner Senior Lecturer in Old Age Psychiatry, St Charles Hospital, London original

papers 